\title{
Nominal vs. Verbal -ing Constructions and the Development of the English Progressive
}

\author{
Artemis Alexiadou ${ }^{1}$ \\ ${ }^{1}$ University of Stuttgart, Institute of English Lingustics, Germany \\ Correspondence: Artemis Alexiadou, University of Stuttgart, Institute of English Lingustics, Keplerstr. 17, 70174 \\ Stuttgart, Germany. Tel: 49-711-6858-3121. E-mail: artemis@ifla.uni-stuttgart.de
}

Received: November 27, 2013

Accepted: December 16, 2013

Online Published: December 18, 2013

doi:10.5430/elr.v2n2p126

URL: http://dx.doi.org/10.5430/elr.v2n2p126

\begin{abstract}
In this paper, I examine nominal and verbal -ing forms in English and discuss aspects of their historical development. In particular, I investigate certain differences between verbal and nominal gerunds in comparison with the present participle with respect to what I call here gradience in verbal traits.

I put forward the following hypothesis. Diachronically, the nominal component of both nominal and verbal gerunds relates to the nominal origin of both forms, namely an Old English derived nominal in -ung/-ing. The 'more verbal' component of the verbal gerund relates to certain aspects of the diachronic development of the English progressive. The changes in the development of the progressive in fact resulted in the emergence of the verbal gerund with parallel continuation of the Old English nominal in -ung/-ing and the Old English participle.

After reviewing the development of English progressive, I will present diachronic and synchronic evidence that the original nominal pattern of the progressive acquired verbal traits. I will then show how this influenced the development of the two gerund types. I will then turn to a structural analysis of the constructions under investigation, which can be summarized as follows: synchronically, the gradience in verbal traits is accounted for on the basis of variation in the internal functional structure of the elements under investigation. On this view, the presence of verbal characteristics is linked to the presence of certain structural layers standardly associated with verbal clauses. Deverbal formations split into several subtypes depending on the number and the type of the layers these contain. This is expressed within a system that views word/category formation as a result of processes operating in specific syntactic structures, which contain the root as the minimal element that enters word formation (Alexiadou 2001, Alexiadou, Iordachioaia \& Soare 2010, Borer 2013, Embick 2010, Marantz 1997, and others).
\end{abstract}

Keywords: Nominal gerund, Verbal gerund, Progressive, Participle

\section{Introduction}

The syntactic nature of structures showing a categorially ambiguous behaviour, such as nominalizations, has not been easy to determine within most approaches formulated in the spirit of Government and Binding (GB) theory, as the distinctions between syntactic phenomena that merely echo lexical information and those that result from an actual syntactic operation is sometimes blurred due to miscellaneous factors. In fact, the tension between the lexicon and the syntactic component is natural under any approach assuming a separate lexical component, starting with Chomsky (1970). Such a viewpoint is more or less standard in many GB approaches, which suggest that the computational system of the grammar operates on items chosen from a/the Lexicon. In the development of GB, the tension between the various components of the grammar (Lexicon and Syntax) has had as a result the constant re-examination of the division of labour between the components. In particular Chomsky's Remarks on Nominalization (1970) suggested that at least certain nominalizations should be lexically derived, such as nominal gerunds, giving birth to the lexicalist position. On the other hand, verbal gerunds are taken to be transformationally related to their verbal source.

This paper contributes to this debate by examining the diachronic development of English gerunds and their relationship to the English progressive. I will propose that both types of gerunds are syntactically derived from a verbal source. However, these differ in terms of their internal functional structure (see Alexiadou 2001, Alexiadou, Iordachioaia \& Soare 2010 for details). 


\section{1 -ing environments in English}

As is well known, there are (at least) three environments where the -ing morpheme appears in English. These are briefly illustrated below. (Note 1) A first environment where -ing is found in English is the present participle, whose primary function consists of combining together with the auxiliary BE to form the progressive (1). Further functions of the present participle include its use in reduced relatives (2), its use as the complement of verbs like begin, perception verbs, and its use as an attributive modifier.

(1) John is walking

(2) The train now standing at Platform 5

Second, -ing appears within verbal gerunds as in (3): (Note 2)

(3) John's destroying the book annoyed everybody

Finally, the third environment is the so called nominal gerund (or mixed nominalization) as shown in (4):

(4) John's destroying of the book annoyed everybody

The above constructions pose certain important puzzles for the traditional distinction between verbs, nouns and adjectives. It is typically assumed that there is a small number of primitive, universal grammatical categories: $\mathrm{N}$ (noun), V (verb), A (adjective) and P (preposition). Each is taken to have a number of prototypical/distinct properties. However, constructions such as the ones illustrated above, are referred to as trans-categorial or simply mixed category constructions, as they do not seem to fit well with the basic distinction in categories. These constructions involve elements that seem to be core members of more than one category simultaneously. This is particularly clear for the two gerund types which show mixed verbal/nominal properties, the former being more 'verbal' than the latter (see Chomsky 1970, Ross 1972, Houston 1985 and others), raising the question of how these two relate to the progressive, which bears the same form but has clearly verbal traits.

In what follows, I briefly summarize the similarities and the differences between the two types of gerunds, see also Alexiadou, Iordachioaia \& Soare (2010).

\subsection{Similarities and differences between nominal and verbal gerunds}

Both types of gerunds are similar in that they both occur in nominal position, as subjects or objects of clauses, cf. (3) and (4). Moreover, they both bear the same semantic relationship to the DPs that accompany them as their corresponding verbs do, i.e. the -of+NP string corresponds to the internal argument of the corresponding verb, and the DP in the Saxon genitive corresponds to its external argument; non-deverbal nominals, e.g. book, do not have such properties. That is both the verb destroy and the nominal destroying refer to an event of destroying, where John is the agent, and the book is the item being destroyed. This suggests that they pattern like Grimshaw's (1990) complex event nominals. Such nominals are systematically like verbs in their argument taking capacities.

However, there are also considerable differences between the two. First, as can be seen in (3) and (4), verbal gerunds take accusative complements, while the complements of the nominal gerunds are introduced by the preposition 'of'. Second, verbal gerunds can be modified by (lower) adverbial modifiers. (Note 3) Nominal gerunds take adjectival modifiers and do not license adverbial modification (5-6). Adjectival modification is not possible with verbal gerunds:

(5) a. Pat disapproved of me/my quietly leaving the room before anyone noticed

b. *the carefully restoring of the painting took six months

(6) a. His prompt answering of the question

b. *His prompt answering the question

Under the standard assumption that such adverbs are VP modifiers, while adjectives are noun modifiers, this contrast suggests that the verbal gerund contains at least a VP.

A related difference is the fact that verbal gerunds do not have the internal structure of a noun phrase. John's in (3) cannot be replaced by any determiner, while this is possible for the nominal gerunds (7b):

(7) a. *that/the criticising the book annoyed us

b. the destroying of the manuscript annoyed the author

Fourth, no auxiliary can be present within nominal gerunds, while this is possible with verbal gerunds (8a):

(8) a. John's having criticised the play annoyed us 
b. *John's having criticised of the play annoyed us

Finally, while verbal gerunds can be negated by not, not cannot be used to negate the nominal gerund. This is not unexpected if the latter type is more 'nominal' than the former, since not cannot be used to negate a noun (9c):

(9) a. Pat's not having called for a week bothered us

b. *The not processing of the election results created a scandal

c. *The not exam shocked everybody

In general, the three types exhibit what I will call here gradience in verbal traits, see also Alexiadou, Iordachioaia \& Schäfer (2011). That is while they seem to share some verbal-like components, i.e. the presence of arguments, they exhibit other verbal properties to a varying degree. For instance, the object of the verbal gerund bears accusative much like the object of the verb. This is not the case with the objects of nominal gerunds. On the other hand, the 'subject' of the verbal gerund bears genitive (or accusative). Subjects of verbal clauses bear nominative. Furthermore, both VPs and verbal gerunds can be modified by certain adverbs. This is not the case with nominal gerunds. But, verbal as well as nominal gerunds have a nominal distribution. This behavior is summarized in table 1:

Table 1. Properties of verbs, participles, nominal and verbal gerunds

\begin{tabular}{lcccc}
\hline Properties & verb & participle & verbal gerund & nominal gerund \\
\hline denote events & $\sqrt{ }$ & $\sqrt{ }$ & $\sqrt{ }$ & $\sqrt{ }$ \\
take arguments & $\sqrt{ }$ & $\sqrt{ }$ & $\sqrt{ }$ & $\sqrt{ }$ \\
overt subject & $\sqrt{ }($ nom $)$ & $\sqrt{ }($ nom $)$ & $\sqrt{ }($ gen $)$ & $(\sqrt{ })($ gen $)$ \\
accusative object & $\sqrt{ }$ & $\sqrt{ }$ & $\sqrt{ }$ & $*$ \\
inflect for tense, agreement & $\sqrt{ }$ & $*$ & $*$ & $*$ \\
adverbial modification & $\sqrt{ }$ & $\sqrt{ }$ & $\sqrt{ }$ & $*$ \\
article & $*$ & $*$ & $*$ & $\sqrt{ }$ \\
adjectival modification & $*$ & $*$ & $*$ & $*$ \\
use in reduced relative & $*$ & $\sqrt{ }$ & $*$ &
\end{tabular}

The above picture is of particular interest, as it suggests that the distinction between nouns and verbs does not represent a dichotomy. As Ross (1972) observes, there seems to exist a quasi-continuum, a hierarchy of the type illustrated in (10). In this hierarchy, different elements show different degrees of verbal as opposed to nominal traits:

(10) Verb $>$ participle $>$ verbal gerund $>$ nominal gerund/mixed nominalization $>$ common noun

The question that I address here is how we can explain this gradience. My investigation of this phenomenon has both a diachronic and a synchronic aspect to it. Specifically, I claim that diachronically the Modern English -ing forms with nominal distribution (verbal and nominal gerunds) derive from a nominal source, namely a derived nominal in Old English.

The emergence of two nominal subtypes with distinct degrees of verb-ness is due to certain changes relating to the historical development of the English progressive. (Note 4) I will substantiate the hypothesis that it is the progressive that is responsible for the unique position of English among the other Germanic languages in having the gerund construction. The reason for this is that it constitutes an environment where formal identity between the Old English participle and the Old English derived nominal led to a syncretism. The result is the emergence of at least three types in Modern English where -ing appears with distinct properties: the formation of the gerund with parallel continuation of the two Old English constructions, the derived nominal and the participle.

Synchronically, the gradience in (10) reflects differences in the type and number of layers of functional structure (i.e. Voice, Aspect, Tense, Number etc) contained within the various constructions. The elements in the left side of the hierarchy contain more functional material than the elements in the right side of the hierarchy. Moreover, the elements in the left differ from the elements in the right in that the former combine with Tense and Complementizers, while the latter combine with determiners. The layers present in the structural architecture determine the semantic-syntactic properties of the constructions. For the environments discussed here, what determines their differences is the variation in the internal functional structure these contain, along the lines put forth in Alexiadou (2001), Alexiadou, Iordachioaia \& Soare (2010), and Alexiadou, Iordachioaia \& Schäfer (2011). 
The paper is structured as follows. Section 2 presents the relevant aspects of the diachrony of the English progressive. Section 3 presents diachronic and synchronic evidence that the original nominal pattern of the progressive acquired verbal traits. Section 4 presents aspects of the development of the two gerund types. Section 5 presents the structural analysis of the constructions. Section 6 concludes my discussion. The Appendix raises some issues to be pursued in future research.

\section{The diachronic development of the progressive (Note 5)}

The development of the English progressive has been controversially discussed by English historical linguists. I will not go into the details of this debate here, but I will concentrate on those aspects that are relevant for the hypothesis that I am pursuing.

As is well known, there are two constructions in Old English that seem to be related to the Modern English progressive, the one in (11) and the one in (13), cf. Jespersen (1931), Visser (1973), Houston (1985), Dal (1952), Nickel (1966), Traugott (1972, 1992), Scheffer (1975), Elsness (1994) and others. I refer to the construction in (11) as the nominal pattern, and to the one in (13) as the participial pattern.

The nominal pattern consists of the auxiliary BE followed by the preposition 'on' which precedes a deverbal nominal in -ung. The complements of this nominal, whenever present, bear genitive case.

$$
\begin{aligned}
& \text { gyrstandæ ic wæs on huntunge } \\
& \text { yesterday I was on hunting } \\
& \text { (Ælfric Colloquium 68, Garmonsway ed. 1938) }
\end{aligned}
$$

(11) roughly means that the subject, 'I', is located in the midst of doing something, namely 'hunting'.

Old English -ung deverbal nouns did not differ syntactically from common nouns. They appear in contexts where common nouns appear, take modifiers in the form of adjectives, demonstratives and pronouns, and their objects appear in the genitive, as shown in (12).

$$
\begin{aligned}
& \text { oftrædlice rædinga haligra boca } \\
& \text { frequent readings holy-gen books-gen }
\end{aligned}
$$

The participial pattern consists of the auxiliary BE followed by the present participle which ends in -ende, which agreed with the subject in phi-features. Note here that most examples cited from Old English with the participial construction mostly contain intransitive verbs as in (13). However, there are examples containing transitive verbs, and their objects surface with accusative case.

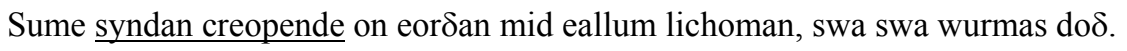

Some creep on the earth with their whole body, as worms do.

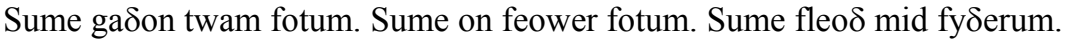

Some go on two feet, some on four feet, some fly with wings.

(Ælfric's Lives, I, 52-55)

The question of whether (11) or (13) is the source of the Modern English progressive is debatable. The evidence seems to suggest that (11) is actually the form underlying the modern progressive. A first piece of evidence comes from the observation that if the first verbal form in (13) were translated with 'are creeping', the translation would not be accurate, as the participial construction is used to express a generic characterization, not the active progressive meaning of the modern progressive. Hence, it seems unlikely that the meaning of the modern progressive is related to the construction in (13). Moreover, according to Mossé (1938), the participial construction is very rare in Old English, occurring most frequently in translations from Latin than it occurs in texts written originally in the language, such as the Chronicles and the Beowulf.

In the course of the history of English, both the above patterns underwent a number of changes. Those most notably took place during the Middle English period (ca. 1100-1500) and I briefly summarize them here, as they have been extensively documented in the aforementioned references.

\subsection{Changes affecting the nominal pattern}

By the 13th century all deverbal nominal formations in English end in -ing. In fact, feminine -ung forms become formally identical to masculine -ing forms which express concrete objects. This is due to a number of morphophonological changes that affected English nouns such as the loss of gender. 
A further important change is that the construction in (11) appears with a reduced $a$ before the -ing form, see (14):

$$
\text { He was a-hunting }
$$

' $\mathrm{A}$ ' is considered a remnant of the full preposition; in fact there is a stage where we find the -ing form construction preceded by 'an' or 'in' instead of 'on' (15a-b).
a. He wes an-slæting
(Layamon, 12305, 1205)
b. He was in hontyng
(later in the text)

A further change is that English nouns lose case morphology. The genitive complements of -ung/-ing nominals were replaced by of $+N P$, cf. Visser (1973). of $+N P$ spread in the progressive, since that also contained a deverbal nominal.

As a result of the above described changes, the nominal pattern has now the form in (16):

$$
\text { Auxiliary be + Preposition (a) + Deverbal Nominal in -ing + of + NP }
$$

\subsection{Changes affecting the participial construction}

The most important change that we find with the pattern in (13) concerns the form of the participle. In particular, Old English -ende has already become -inde in late West Saxon. Then the final /e/ or schwa got lost in levelling. By the mid 15th century, -ind has been replaced by -ing in the south of England. As a result, a form like irnende is now running (cf. Houston 1991, Moore, Meech \& Whitehall 1935).

Because of these morpho-phonological changes, the participial and the nominal pattern ended up looking identical in form. Most importantly, they both contain a (verb) stem to which the suffix -ing is added:

(17) Auxiliary be + Present Participle in -ing (hunting)

\subsection{The importance of these changes for nominalization patterns}

As a result of the changes described in the previous section, the Modern English -ing is related both to the Old English -ung and the Old English -ende. In Old English, these were distinct suffixes and had strict distributional restrictions: the former appeared with deverbal nominals, the latter with participles. But after the changes that took place in the Middle English period, there is only one suffix which can appear in both environments. It is an interesting question whether speakers treat the two instances of -ing as one morpheme which can appear in various environments, or whether they treat the two instances as two distinct morphemes. The main hypothesis that I am developing here relies on the intuition that speakers treat -ing as two dinstict pieces, as they associate distinct semantic properties with each of these three intantiations: -ing realizes Aspect in the case of the progressive, but a nominalizing head in the case of the nominal gerund. In sections 3 and 4 further evidence for this view will be presented. In particular, as we will see in section 3, Wessex English treats all -ing formations as nominal. In section 4, we will see that the existence of the so called intermediate type, e.g. the reading the book, suggests that actually the verbal gerund is indeed the outcome of the syncretism between the participle and the nominal form.

Now if the preposition $a$ in (16) were omitted, the two patterns could no longer be distinguished from one another. In fact, this seems to be an accurate description of what has actually happened. If the two patterns can no longer be distinguished from one another, they get confused in the sense that the one is influenced by the other in some of its properties. Crucially, this has as a result that the nominal form 'acquired verbal traits'. These include: (i) appearance of direct objects and (ii) co-occurrence with adverbs and periphrastic auxiliary forms. A further consequence of these changes relates to the case the objects of the two -ing forms bear. With the participle (17), the objects surface with accusative. With the nominal (16), the objects bear (prepositional) genitive.

But how did this happen? A possible development could have had the following form. The two patterns look alike. At least in one environment they (almost) substitute for one another in usage. There is in fact evidence, cited in Elsness (1994), that the participial construction becomes more and more similar to the nominal one in meaning. Certain of these examples are presented in the next section. As a result, speakers attribute properties of the participial construction to the nominal one. Hence, the nominal pattern tends to become more verbal. In other words, although what underlies the Modern English progressive is a nominal source, this nominal source acquired verbal traits due to its formal identity with the present participle in one environment in which both constructions could be used.

In the next section, I present further evidence that the progressive is a nominal construction (see also Bolinger 1971) which acquired verbal traits due to the just described syncretism. The type of evidence I discuss shows that in English dialects the progressive appears still in its original form, and it further demonstrates that during the early Modern English period progressives with prepositions co-occur with progressives without prepositions, a fact suggesting that the two patterns were no longer distinguishable from one another. The evidence cited below further 
suggests that the development took place over a long period of time and involved competition between the two constructions (Kroch 1989, 2001 and references therein).

\section{Diachronic and dialectal evidence (Note 6)}

As can be seen in (18), the nominal pattern appears in contexts where otherwise a common nominal would appear, e.g. following a preposition in (Early) Modern English:

(18) rend not my heart for naming of my Christ (Marlowe, Doctor Faustus, 1604)

Most importantly, however, we find the nominal pattern in verbal clauses with progressive meaning, as shown in the examples in (19), which spread from the 17th to the 20th century: (Note 7)

a. I am a young beginner and am building of a new shop

(Ben Johnson, Alchemist, 1610)

b. I was dreaming that I sat alone in a solitary place, and was bemoaning of the hardness of my heart

(Bunyan, Pilgr. Progr (Collins) 234, 1678)

c. A company of waggish boys were watching of frogs at the side of a pond

(Addison, Spect. , no 23.,1711)

d. he, appear'd with a Majesty and a Loftiness which he never us'd to wear when he was taming of Monsters upon the earth

(Boyer \& Littlebury, tr. Adventures of Telemachus, 292, 1728)

As the examples in (20) show, the prefix $a$ - can also appear before the -ing form:

a. He had been a hunting of the hare

(Berners Froissart VI 54, 1523-1525)

b. So he had them into the slaughter-house, where was a butcher a killing of a sheep

(Bunyan, Pilg.Progr. 187,2., 1678)

c. 'They are a-twigging of you Sir', whispered Mr Weller. 'Twigging of me, Sam!' replied Mr. Pickwick, 'what do you mean by twigging me'

(Dickens Pickwick, XX 274, 1837)

d. 'You pinch me, Sir'. 'You're a- hurting of me'

(Dickens, master Humphrey's Clock I, 20, 1840)

e. He was by nature unfortunate and was always a- missing of everything

(W.F. de Morgan, Joseph Vance, ch 1., 1906)

f. You're dirt and can't 'ardly understand what I am a-sayin' of, but I'appens to like you

(M. Allingham, More Work for the Undertaker 230, 1949)

Furthermore, the 'auxiliary be +ing $+o f N P^{\prime}$ pattern can occur in close parallel with a progressive without any preposition, as shown in (21):

(21) 'And this Gabriel Holmes did advise to have had two houses set on fire, one after the another, that while they were quenching of one, they might be burning another.

(in Visser 1973: 2003, Pepys's Diary, dated July 4th 1666)

Preliminary investigations of this pattern exist, and are presented here in tables 2 and 3, drawn from Houston (1985) and Elsness (1994). Elsness' investigation is made on the basis of the Helsinki corpus of Earlier English.

Table 2. Houston's (1985) corpus: (Note 8)

\begin{tabular}{cccccc}
\hline Form without a preposition & 15 th & 16 th & 17 th & 18 th & 19 th \\
& 1.7 & 5.5 & 2.1 & 3.2 & 15.7 \\
Form with a preposition & 0.4 & 0.8 & 0.0 & 3.3 & 3.3 \\
\hline
\end{tabular}


Table 3. Elsness (1994)

\begin{tabular}{llll}
\hline & Period I & Period II & Period III \\
& $1500-1570$ & $1570-1640$ & $1640-1710$ \\
\hline P before V & 12.10 & 9.6 & 6.0 \\
P before O & 3.0 & 1.9 & 2.0
\end{tabular}

We can observe that the pattern without a preposition is more frequent. However, the pattern with a preposition rises slightly in frequency as we come closer to the 18th and 19th century. As we will see in section 4, this correlates with the emergence of the verbal gerund.

Furthermore, the nominal form is preserved in dialects. A case in point is the variety of English spoken in the south-west part of England referred to here as Wessex English (22).

$$
\begin{array}{cl}
\text { I were } \underline{\boldsymbol{a} \text {-peeling } \text { of } \text { the potatoes }} & \text { Wessex English } \\
\text { (with a different spelling) } & \text { (Gachelin 1991: 223) }
\end{array}
$$

In this dialect, the same pattern, i.e. a nominal surrounded by two prepositions appears in clearly nominal environments (23):

$$
\begin{array}{lll}
\text { a. My own a-decken ov my own } & \text { nominal gerund } \\
\text { my own-way a-dressing of my darling } & \\
\text { b. That wer vor hetten o'n } & \text { verbal gerund } \\
\text { that was for hitting him } &
\end{array}
$$

This suggest that for this dialect all -ing forms are equally nominal.

On the other hand, in other dialects of English, there are no instances of $a$-stem-ing which occur in nominal contexts, as opposed to Wessex English, showing that the nominal pattern gradually extended its use to the verbal domain. A case in point is the dialect spoken in the Appalachian mountains referred to as Appalachian English. As (24) shows, in this dialect the participle is still preceded by ' $a$ ':
a. he was a-tellin' the truth
b. she's a-gettin' the black brown pony
(Wolfram 1991: 231)

Interestingly, Appalachian English does not permit $a$ - prefixing when the -ing form is clearly nominal (25) or adjectival (26b).
a. *He saw the a-shootin'
b. *He watched their a-shootin'
a. *He got sick from a-working so hard
b. *The hunters shot the a-runnin' bear (Wolfram 1991:233)

In fact, outside of the progressive, one finds a-prefixing with uses of -ing that correspond to those of the present participle in standard English (27):

\section{(27) A bear come a-running}

There are also morpho-phonological restrictions blocking the appearance of $a$ - in Appalachian English (see Wolfram 1991). For instance, the prefix cannot appear if the initial syllable is not stressed:

*He was a-discovering a bear in the woods

If the verb begins with a vowel, then $a$-prefix typically does not occur either:

*John was a-eating his food.

Such phenomena suggest that the presence of the preposition has been re-analyzed as a morpho-phonological well-formedness requirement on verbal forms. (Note 9) The case of Appalachian English is very important for the hypothesis advanced here. While the progressive in Wessex English still maintains its nominal/prepositional origin, the progressive in standard English does not show any overt markings of this origin. However, the progressive in 
Appalachian English provides the link between the two patterns, the nominal one and the overtly verbal one, in that it shows how the nominal one becomes more verbal. For instance, the prefix is preserved, but only on verbal forms.

The development of the progressive is summarized in Table 4. (Note 10)

Table 4. The development of the English progressive

Old English

Middle English

$$
\text { Auxiliary be }+ \text { Preposition (on) }+ \text { Deverbal Nominal in -ung/-ing }+\mathrm{NP}_{\text {gen }}
$$

Auxiliary be + Preposition (a) + Deverbal Nominal in -ing + of + NP becomes colloquial in Modern English, later dialectal \& substandard

I were a-peeling of the potatoes (Wessex English)

Standard Modern English Auxiliary be + V-ing + NP

I was peeling the potatoes

In the next section, I discuss how this diachronic development had as a result the development of the verbal gerund, but see de Smet (2008) for an alternative explanation.

\section{Establishment of the verbal gerund}

Thus far I have claimed that due to the syncretism described in sections 2 and 3 the nominal -ing in the progressive acquired the capability to operate as a verb taking an accusative object; the obvious marker of the nominal pattern, namely $a$-prefixation, either became obsolete, which is the case in Standard English or merely a marker of verb-ness, which is the case in Appalachian English. What remains to be seen is instances of nominal -ing bearing verbal properties in environments other than the progressive, i.e. the emergence of the verbal gerund.

Clearly, the nominal -ing maintains its nominal character in nominal environments (30). The only difference here is that genitive in the complement of Old English -ung/-ing nominals is replaced by of $+N P$.

(Chauser, Troil. F 243)

The DP denoting the agent of the action bears genitive in Old, Middle and Modern English. Besides a noun, a possessive pronoun can be used. Hence Old English derived nominals are Modern English nominal gerunds. Also the participle is still maintained in its use in e.g. apposition.

(31) is an example which shows the acquisition of verbal traits in nominal environments, which is the first verbal trait that can be witnessed. The -ing form appears in the complement domain of a preposition, a position reserved for noun phrases. Such examples occur as early as the mid 15th century, that is after the period that led to the syncretism between the participle and the nominal:

$$
\text { if he graunt my bodyr Edmund ys son in recompence for takyng my brother Edumds son }
$$

$$
\text { (Paston Letters, p. } 616 \text { vol 2, 1450) }
$$

Several such examples are cited in Visser (1973) and in Houston (1985). Adverbs and auxiliaries seem to be a much later development. In fact the rise of verbal traits associated with verbal gerunds correlates with the rise in the use of the progressive throughout the Modern English period.

Further evidence for the hypothesis that the syncretism between the nominal and the participle in the progressive led to the emergence of the verbal gerund comes from the observation that one finds strings containing a direct object together with a definite article, i.e. both 'the reading the book', the so-called intermediate type. Such forms co-occur with the nominal and the verbal gerund in Early Modern English and until the 20th century, cf. (32-33).
a. You need not fear the having any of these lords
b. The difficulty in the getting the gold
(Shakesp. Merch I, ii, 109, 1596)
a. The gathering of principles out...
(Sam. Butler Erewhon Revisited, 1902)
b. From the daily reading of the bible
(Rich. Hooker, Laws of Eccl. 1597
(Frederik Harrison, John Ruskin 1902)

Table 5 presents figures of the distribution of the three types from the 15th to the 19th century (from Houston 1985: 185). As can be seen from these figures, the intermediate type is most frequent at the period where verbal and nominal gerunds are almost equally frequent, namely in the 17th century. In the 19th century, there are occurrences 
of the intermediate type after a period where no such figures are available. Naturally Houston's corpus is limited. The figures concerning the three gerund types, however, are suggestive of a more general pattern of language change. Similar effects are found with the emergence of $d o$-support in English, whose use was variable but increased over time, but which shows different rates and different paths depending on the type of construction it is found, e.g. declarative as opposed to interrogative (see Kroch 1989).

Table 5. Distribution of gerunds, as nominal, verbal and intermediate

\begin{tabular}{llllll}
\hline & 15 th & 16 th & 17 th & 18 th & 19 th \\
\hline nominal gerunds & 86.4 & 69.1 & 32.8 & 21.4 & 37.3 \\
verbal gerunds & 12.2 & 29.9 & 55.0 & 78.6 & 56.8 \\
intermediate & 1.4 & 1.0 & 12.2 & 0.0 & 5.9
\end{tabular}

The intermediate type is no longer available in Modern English, which makes a two-way distinction. However, the fact that it existed at some stage of the language suggests that the hypothesis advanced here is along the right track. There could have been no way for the intermediate form to emerge, if a nominal -ing construction had not acquired verbal traits due to syncretism with a verbal form. This in turn further supports the view that the -ing morpheme, though diachronically different in each case, is reanalyzed synchronically as a type of suffix that can appear in various environments. Depending on the environment it is found different verbal and nominal forms emerge. This will be discussed in the next section.

Note here that the nominal gerunds are not very productive in present day English, where they are replaced by the so called derived nominals, e.g. the destruction of the city instead of the destroying of the city. The nominal gerund and the derived nominal are very similar as far as their properties are concerned, and as Alexiadou, Iordachioaia \& Soare (2010) observe often the nominal gerund form is blocked by the derived nominal: both are modified by adjectives and not adverbs, both can take determiners and both are accompanied by objects introduced by 'of'. This suggests that the language might be re-arranging its nominalization patterns in identifying -ing forms with verbal gerunds and -ion, -al forms with derived nominals. This has certain consequences for the status of -ing, which could be re-analyzed as being a type of morpheme that relates to aspectual projections only, contained within the participle and the verbal gerund, if the nominal gerund becomes obsolete (see section 5.2).

\section{The structural analysis of the three types}

Before I present my structural analysis of the patterns, I will briefly introduce the basic assumptions I am adopting.

\subsection{Theoretical assumptions}

Alexiadou, Iordachioaia \& Soare (2010) have developed a flexible syntactic account that captures the mixed behavior of nominalizations across languages. According to their analysis, all deverbal nouns contain at least a VP (VoiceP in (34)). They crucially differ in the type and number of additional verbal and nominal projections they contain. The picture that emerges from this work is summarized in (34), where the parentheses indicate the projections that may be missing in some nominalizations:

$$
\mathrm{DP}>(\mathrm{NumP}>\text { ClassP }>\mathrm{nP})>(\text { AspP })>\text { VoiceP }
$$

Nominalizations differ in terms of two parameters. The first parameter concerns the presence of a nominalizer. If a nominalizer is not available, the nominalization lack nominal internal properties, and their external syntax is accounted for by the DP layer. If a nominalizer is included, a second parameter characterizes variation with respect to the height of attachment of the nominalizer. Specifically, a nominalizer can attach to (and thus nominalize) either the VoiceP or the AspectP layer.

The funectional heads included in the structure are associated with a distinct set of properties. In particular, v, Voice and Aspect create a verbal/eventive environment in that they bear the following features (see also Kratzer 1996, Chomsky 1995, Marantz 1997, Alexiadou, Anagnostopoulou \& Schäfer 2006, to appear, and others):

(i) $\quad \mathbf{v}$ is the locus of event implications

(ii) Voice is the locus of features relevant to the licensing and interpretation of external arguments/agents. It bears accusative Case features for the object. It comes in two types: one introducing an external argument, and one that does not introduce an external argument. 
(iii) Aspect contains features that relate to the semantic properties of the event denoted by a predicate; for instance, perfective for a completed event, imperfective for an ongoing event. The presence of AspectP is linked to the licensing of lower adverbs (Alexiadou 2001).

From this perspective, nominal formation involves some part of (34) embedded under D(eterminer) or nP. Verbal/clausal formation involves embedding (34) under $\mathrm{T}(\mathrm{ense}), \mathrm{C}$ (omplementizer). The domain containing Asp/Voice is atomic in the sense that it has a certain level of independence. As a result, this domain is found embedded within different categories, verbs, participles and certain nominals and can be negated. In (34), D turns the projection into a definite nominal argument and guarantees that it can occupy nominal positions. However, it is the presence of $\mathrm{nP}$ that turns the internal structure of the projection into a nominal: if $\mathrm{nP}$ is present then, we expect a number of nominal internal properties (see Alexiadou 2001, following Valois 1991, and Alexiadou, Iordachioaia \& Soare 2010).

This view on the nature of deverbal formations suggests that variation in the type and number of projections gives us different types of constructions across languages and within a language. In particular, the variation depends on (i) the number of functional projections included in the structure, i.e. whether T, D, Number, Aspect, Voice or $\mathrm{v}$ are present or not and (ii) the type, i.e. the feature specification of the projections, e.g. whether $\mathrm{v}$ is transitive or not.

With this background, let us consider the structure of the constructions under investigation in some detail.

\subsection{The patterns: structures and properties}

(35) illustrates the structure assumed for verbal gerunds:

$$
\text { [DP [AspectP [VoiceP [vP [Root]]]]] verbal gerund (Note 11) }
$$

We saw that the verbal gerund as verbal internal properties. We can observe that unlike the nominal gerund it resembles the progressive in one important respect: both are compatible with telic events, but they are just as fine with atelic ones. Moreover, a telic event in the verbal gerund can be modified by a for-PP, see (36-37) from Alexiadou, Ioardachioaia \& Soare (2010):

a. John is working now.

b. John's reading books until late in the night worries his mother.

a. John wrote the letter in $\mathbf{3}$ days/*for 3 days.

b. John's writing the latter for $\mathbf{3}$ days annoyed everybody.

Alexiadou, Iordachioaia \& Soare (2010) thus concluded that the structure of the verbal gerund contains Aspect, with the suffix -ing contributing and realizing imperfective outer aspect (cf. also Alexiadou 2005). The only nominal layer in the verbal gerund is the DP which explains its nominal external syntax.

In contrast to the verbal gerund, the nominal one inherits the inner aspect of the verb. Inner aspect also correlates with the availability of pluralization: if the verb is [+bounded], the plural is available; if the verb is [-bounded], the plural is unavailable, see (38) from Alexiadou, Iordachioaia \& Soare (2010). This also means that the nominal gerund does not trigger aspect shift. In this situation, a syntactic Aspect projection is unmotivated:

a. I heard of repeated killings of unarmed civilians.

b. *The repeated fallings of the stock prices induced their further decline.

The explanation for these facts lies in the sensitivity of the nominalizer -ing to the type of event included within VoiceP, see also Borer (2005) for discussion.

Table 6 relates the functional material contained in (34) to the properties associated with verbal gerunds, while table 7 relates the properties associated with nominal gerunds to the functional material they contain:

Table 6.

\begin{tabular}{lcc}
\hline Properties & verbal gerund & Functional Structure \\
\hline article & $*$ & D contains 's', no nP \\
\hline adjectival modification & $*$ & No nP \\
\hline adverbial modification & $\sqrt{ }$ & AspectP \\
\hline overt subject & $\sqrt{ }($ gen $)$ & Spec,DP movement from Spec, vP \\
\hline accusative object & $\sqrt{ }$ & Voice [+transitive] \\
\hline
\end{tabular}


Table 7.

\begin{tabular}{lcc}
\hline Properties & nominal gerund & Functional Structure \\
\hline article & $\sqrt{ }$ & $\mathrm{D}$ \\
\hline $\begin{array}{l}\text { adjectival } \\
\text { modification }\end{array}$ & $\sqrt{ }$ & $+\mathrm{nP}$ \\
\hline adverbial modification & $*$ & no AspectP \\
\hline overt subject & $\sqrt{ }($ gen $)$ & Spec,DP \\
\hline accusative object & $*$ & Voice [-transitive]
\end{tabular}

A crucial difference between the two gerund types concerns the fact that certain nominal gerunds contain number, and hence can pluralize, see (39) above, while verbal gerunds lack number and thus can never pluralize. The presence of $\mathrm{D}$ is a functional element that makes the atomic structure in (34) to behave externally as a nominal. Szabolcsi (1994), Longobardi (1994) and others have argued that D is like C in that they both turn their complements into arguments, in particular in view of the fact that only DPs and CPs can function as arguments. Articles and complementizers are subordinators. On the other hand, $\mathrm{nP}$ takes VoiceP as its complement and is responsible for the presence of nominal internal properties, e.g. adjectives etc. Those nominal gerunds that have plural morphology are analyzed in Alexiadou, Iordachioaia \& Soare (2010) as containing a Classifier Phrase, a phrase that introduces individuation, see Borer (2005). A further difference between nominal and verbal gerunds is that verbal gerunds can assign accusative, while nominal gerunds instantiate a nominal pattern of Case assignment. This is related to the fact that these are taken to instantiate some form of passivization (Alexiadou 2009, Borer 2013).

Turning now to the discussion of the structure of the progressive, we can observe the following. The structure of the Old English progressive contains a version of (34), namely a nominal sub-structure, containing nP, embedded under a preposition. This complex appears in in the complement domain of BE. In contrast, the structural represenation of the Modern English progrssive is as in (40), i.e. it is very similar to the structure assumed for the verbal gerund.

$$
[\mathrm{XP}[\text { AspectP }[\mathrm{VoiceP}[\ldots]]]] \quad \text { participle }
$$

Table 8.

\begin{tabular}{lcc}
\hline Properties & participle & functional structure \\
\hline article & $*$ & no D \\
\hline adjectival modification & $*$ & no nP \\
\hline adverbial modification & $\sqrt{ }$ & AspectP \\
\hline overt subject & $\sqrt{ }$ & Voice[+transitive] \\
\hline accusative object & $\sqrt{ }$ & Voice [+transitive] \\
\hline tense/agreement & $*$ & no TP \\
\hline
\end{tabular}

The structure of the Modern English progressive then contains a version of (40) embedded under BE, see Bjorkman (2011) for further discussion.

\section{Conclusions}

In this paper I examined the gradience in verbal traits exhibited by the nominal and verbal gerund in comparison with the present participle. I claimed that the nominal component of gerunds relates to the nominal origin that underlies both gerund forms, which is an Old English deverbal nominal in -ung/-ing taking an NP complement in the genitive.

I presented evidence for the hypothesis that the verbal component relates to the diachronic development of the progressive in English. The English progressive is relevant as it provides an environment that led to confusion. While the progressive derives from the nominal pattern, some progressives acquire verbal properties as a result of a confusion between the nominal construction and the participial one. The latter underwent a number of morpho-phonological changes, the result being that both patterns contained identical forms. The above confusion results in two nominal -ing forms: the verbal gerund and the nominal gerund/mixed nominalization. 
a. Auxiliary be + Preposition (on) + Deverbal Nominal in -ung/-ing $+\mathrm{NP}_{\text {gen }}$

b. Auxiliary be + Present Participle in -ende ( + Object bearing Accusative)

Synchronically, the gradience in verbal traits is captured in terms of variation in functional structure and the properties of the constructions are determined by the height of attachment of the -ing morpheme.

\section{Acknowledeges}

Earlier versions of this paper were presented at seminars at the Universität Stuttgart, FU Berlin, NELS 32 in NYU, and Georgetown University. I thank the audiences for their comments and suggestions. I am indebted to two anonymous reviewers and the editors of this journal for their input. A DFG grant to project B1 The form and interpretation of derived nominals of the SFB 732 Incremental Specification in Context as well as the grant AL $554 / 1$ are hereby acknowledged.

\section{References}

Abney, S. (1987). The English noun phrase in its sentential aspect. Ph.D. dissertation, MIT.

Alexiadou, A. (2001). Functional structure in nominals: nominalization and ergativity. Amsterdam: John Benjamins.

Alexiadou, A. (2009). On the role of syntactic locality in morphological processes: the case of (Greek) derived nominals. In A. Giannakidou \& M. Rathert (Eds.), Quantification, definiteness \& Nominalization (pp. 253-280). Oxford: Oxford University Press.

Alexiadou, A. E. Anagnostopoulou \& F. Schäfer. (2006). The properties of anticausatives crosslinguistically. In M. Frascarelli (Ed.) In Phases of Interpretation, (pp. 187-211). Berlin: de Gruyter.

Alexiadou, A. E. Anagnostopoulou \& F. Schäfer. (to appear). External arguments in transitivity alternations: a layering approach. Oxford: Oxford University Press.

Alexiadou, A., G. Iordachioaia \& F. Schäfer. (2011). Scaling the variation in Romance and Germanic nominalizations. In P. Sleeman \& H. Peridon (Eds.), The noun phrase in Romance and Germanic, (pp. 25-40). Amsterdam: John Benjamins.

Alexiadou, A., G. Iordachioaia \& E. Soare. (2010). Number/Aspect interactions in the syntax of nominalizations: a distributed Morphology approach. Journal of Linguistics 46, 537-574. http://dx.doi.org/10.1017/S0022226710000058

Arnaud, R. (1998). The development of the progressive in 19th century English: a quantantive survey. Language Variation and Change 10: 123-152. http://dx.doi.org/10.1017/S0954394500001265

Bjorkman, B. (2011). BE-ing default: the morpho-syntax of auxiliaries. Ph.D. dissertation, MIT.

Bolinger, D. (1971). The nominal in the progressive. Linguistic Inquiry 2, 246-250.

Borer, H. (2005). The normal course of events. Oxford: Oxford University Press. http://dx.doi.org/10.1093/acprof:oso/9780199263929.001.0001

Borer, H. (2013). Taking form. Oxford: Oxford University Press.

Bybee, Jane, R. Perkins \& W. Pagliuca. (1994). The evolution of grammar. Chicago: The University of Chicago Press.

Chomsky, N. (1970). Remarks on nominalization. In R. Jacobs \& P. Rosenbaum (Eds.), Readings in English Transformational Grammar (pp. 184-221). Waltham, Mass.: Ginn and Company.

Chomsky, N. (1995). The minimalist program. Cambridge, Mass.: MIT Press.

Dal. I. (1952). Zur Entstehung des englischen Participium Praesentis auf -ing. Norsk Tidsskrift for Sprogvidenskap $16,5.116$.

de Smet, H. (2008). Functional motivations in the development of nominal and verbal gerunds in Middle and Early Modern English. English Language and Linguistics 12, 55-102. http://dx.doi.org/10.1017/S136067430700250X

Elsness, J. (1994). On the progression of the progressive in early Modern English. ICAME Journal 18, 5-25.

Embick, D. (2010). Localism and globalism in morphology and phonology. Cambridge: Mass, MIT Press. http://dx.doi.org/10.7551/mitpress/9780262014229.001.0001 
Gachelin, J.-M. (1991). Transitivity and intransitivity in the dialects of South-West England. In P.Trudgill \& J.K. Chambers (Eds), Dialects of English (pp. 218-228) Longman: London.

Grimshaw, J. (1990). Argument Structure. Cambridge, Mass.: MIT Press.

Harley, H. \& R. Noyer. 1998. Mixed nominalizations, short verb movement and object shift in English. In Proceedings of NELS 28, 143-159.

Houston, A. (1985). Continuity and change in English morphology: the case of variable -ing. Ph.D. dissertation, University of Pennsylvania.

Houston, A. (1991). A grammatical continuum for ING. In P.Trudgill \& J.K. Chambers (Eds.), Dialects of English (pp. 241-257). Longman: London

Jespersen, O. (1931). A Modern English grammar on historical principles. George Allen \& Unwin Ltd: London.

Kratzer, A. (1996). Severing the External Argument from its Verb. In J. Rooryck \& L. Zaring (Eds.), Phrase Structure and the Lexicon (pp.109-137). Dordrecht: Kluwer. http://dx.doi.org/10.1007/978-94-015-8617-7_5

Kroch, A. (1989). Reflexes of grammar in patterns of language change. Language Variation and Change 1, 199-244. http://dx.doi.org/10.1017/S0954394500000168

Kroch, A. (2001). Syntactic change. In M. Baltin \& C. Collins (Eds.), Handbook of Syntax (pp. 699-729). Oxford: Blackwell.

Lees, R. (1960). The grammar of English nominalizations. The Hague: Mouton.

Longobardi, G. (1994). Reference and proper names: a theory of N-movement in syntax and LF. Linguistic Inquiry $25,609-665$.

Marantz, A. (1997). No escape from Syntax: don't try morphological analysis in the privacy of your own lexicon. University of Pennsylvania Working Papers in Linguistics 4 (2), 201-225.

Moore, S., S.B. Meech \& H. Whitehall. (1935). Middle English dialect characteristics and dialect boundaries. University of Michigan Language and Literature Studies.

Nickel, G. (1996). Die Expanded Form im Altenglischen. Neumunster: Karl Wachholtz Verlag.

Ross, J. (1972). The category squish: endstation Hauptwort. CLS 8, 316-328.

Scheffer, J. (1975). The progressive in English. Amsterdam: North Holland.

Szabolcsi, A. (1994). The Noun Phrase. In F. Kiefer \& K. Kiss (Eds.), The Syntactic Structure of Hungarian (pp. 179-224). New York: Academic Press.

Traugott, E. (1972). A history of English Syntax: a transformational approach to the history of English sentence structure. New York: Holt, Rinehart \& Winston.

Traugott, E. (1992). Syntax. In R.M. Hogg (Ed.), Cambridge History of English syntax 1: The beginnings to 1066 (pp. 168-289). Cambridge: Cambridge University Press. http://dx.doi.org/10.1017/CHOL9780521264747.005

Valois, D. 1991. The internal structure of DP and adjective placement in French. Proceedings of NELS 21, 367-382.

Visser, F.Th. (1973). A historical syntax of the English language. E.J.Brill: Leiden. 


\section{Appendix: further issues}

\section{Other prepositions used in the progressive}

' $a$ ' is not the only preposition found in the nominal pattern. The prepositions 'upon' and 'in' can also be present. I am upon writing a little treatise to present to the Duke

(Pepy's Diary, 31 Dec., 1661)

The carriage was in waiting to take him to dinner

(Thackeray, Van. Fair, 1847)

The combinations of the above prepositions together with an -ing form also mean that a person $\mathrm{X}$ is engaged in a certain activity. Implications may differ in the sense that the expressions may refer to various phases of the activity or may denote a less or more specific relation to the activity, depending on the preposition used, since the individual prepositions have different meanings.

\section{Related constructions in other languages}

The nominal/prepositional pattern is found in other Germanic languages as well with a meaning that comes close to that of the English progressive. (3) illustrates this for the German dialect spoken in the area of Köln:

(3) a. Ich war das Buch am Schreiben

I was the Book on read-infinitive

I was reading the book

b. Ich war noch beim Schwimmen

I was still by swim-infinitive

I was still swimming

In (3) the different prepositions have different semantic import and different restrictions on the classes of verbs that can follow them.

(4) illustrates a similar pattern in Dutch, the so called aan-heet construction:

hij is aan het lesen

Er ist am Lesen

$\mathrm{He}$ is on/at reading

Only English, however, has developed the verbal gerund.

Moreover, Celtic languages, e.g. Irish or Welsh, have comparable constructions containing an auxiliary together with a verbal noun to express progressive meaning. It should be kept in mind here that certain researchers have claimed that the English form originated under the influence of Celtic:

$$
\begin{aligned}
& \text { á sé ag snámh } \\
& \text { is he at to-swim } \\
& \text { 'He is swimming' }
\end{aligned}
$$

The object of the verbal noun is in the genitive, not the accusative:

$$
\begin{aligned}
& \text { Tá sé ag ithe aráin } \\
& \text { is he at to-eat of-bread } \\
& \text { 'He is eating bread' }
\end{aligned}
$$

Locational sources of the progressive have been argued to exist in Romance (Spanish and Portuguese), Icelandic, Finnish, Basque, Maltese, Cocama, Jivaro, Haka, Cantonese, Tok Pisin etc. Clearly then, the analysis of the English construction offered here has implications for the analysis of the progressive patterns across languages. Most importantly, these patterns relate to two more general questions that I have not addressed in this paper, namely whether location is a universal component of the progressive or not and how spatial meanings extend to temporal ones (Bybee \& al. 1994). 


\section{Notes}

Note 1. I do not discuss instances of -ing on adjectives, adverbs and prepositions. Presumably these derive from either nominal or verbal uses of -ing.

Note 2. I do not discuss differences between Acc-in and Poss-ing here. (i) illustrates the two subtypes of the verbal gerund. A crucial difference between the two is that the agent bears accusative in (ia), while it is accompanied by the possessive, $\mathrm{s}^{\text {' }}$ in (ib):

(i) a. Him collecting the money led to a disaster

b. His collecting the money led to a disaster

Note 3. The term lower adverbial modifiers refers to what is traditionally called VP modifiers. On the other hand, sentence adverbs, i.e. ,higher' adverbs, are not found within gerunds:

(i) *Pat's fortunately collecting the money rescued the operation

Note 4. Houston (1985) also considers the possibility that the emergence of two nominal -ing forms in English relates to the distribution of such forms in earlier stages of the language in what she calls oblique constructions. Her hypothesis is supported by a sociolinguistic and a historical study. See also Mossé (1938).

Note 5. Elsness (1994), Arnaud (1998) and others note that the progressive really became of general use in the Modern English period, in fact as late as the 19th century.

Note 6. Bolinger (1971) reports that the nominal/prepositional source of the progressive is still visible. For instance, the progressive can be used as a very appropriate answer to a location inquiry:

A: Where's Lou?

B: He's reading/He is at confession/*He reads

Moreover, progressives share to be when conjoined with prepositional phrases:

(ii) They're already in position and waiting for the call

Note 7. Examples taken from Visser (1973).

Note 8. Houston's sources: Cely Papers, Paston Letters (15th century), Writings of John Chamberlaain, St. German's Doctor and Student (16th) century, Verney Papers, Diary of Ralph Josselin, Esses Papers (17th century), Diary of Geremiah Greenman (18th century), Diary of Alfred Jackson, Diary of Mrs. King (19th century).

Note 9. Other such cases that show morpho-phonological sensitivity of prefixes are:

(a) ge-prefixation in German, blocked with be-verbs, etc and

(b) the presence of the augment in Greek Past forms. For many Past forms there is stress shift to the antepenultimate syllable, which can be taken to mean that Stress Shift characterizes past forms. The augment is present in bi-syllabic verbs to carry the stress in the antepenultimate syllable.
(i) graf-o
é-graf-a,
é-grap-s-a,
gráf-tik-a,
write-Non Past
write-Imp-Past
write-Perf-Past
write-Nact-Perf-Past

Note 10. The locational source explains why putting a verb in the progressive semantically requires that it be treated as a stative verb.

Note 11. For a diferent approach to the structure of nominal and verbal gerunds within the framework of Distributed Morphology, see Harley \& Noyer (1998). 